\title{
Application and Development Prospects of Dietary Fibers in Flour Products
}

\author{
Wen Han, ${ }^{1,2}$ Sen Ma, ${ }^{1,2}$ Li Li, $^{1,2}$ Xiao-xi Wang, ${ }^{2}$ and Xue-ling Zheng ${ }^{2}$ \\ ${ }^{1}$ Province Key Laboratory of Transformation and Utilization of Cereal Resource, Henan University of Technology, \\ Zhengzhou 450001, China \\ ${ }^{2}$ College of Grain Oil and Food science, Henan University of Technology, Zhengzhou 450001, China
}

Correspondence should be addressed to Sen Ma; masen@haut.edu.cn and Xiao-xi Wang; xxwanghaut@126.com

Received 22 November 2016; Revised 13 February 2017; Accepted 5 March 2017; Published 16 March 2017

Academic Editor: Ji Kang

Copyright (C) 2017 Wen Han et al. This is an open access article distributed under the Creative Commons Attribution License, which permits unrestricted use, distribution, and reproduction in any medium, provided the original work is properly cited.

\begin{abstract}
Dietary fibers are often characterized by high nutritional quality, as they are able to cure many chronic diseases and improve texture, sensory characteristics, and shelf life of foods. Here, the following aspects of dietary fibers have been reviewed: nutritional properties, including the ability to regulate blood sugar levels, effects on microorganisms, antioxidant effect, potential role in losing weight, ability to regulate blood lipids, application in flour products such as bread and Chinese noodles, challenges such as dark color, rough texture, and poor solubility, and potential solutions that include modification methods. The primary purpose of this review is to comprehensively evaluate potential applications of dietary fibers in flour products, addressing common problems and reviewing potential solutions to promote further study and applications of dietary fibers.
\end{abstract}

\section{Introduction}

With growing interest in health-promoting functional foods, the demand for natural bioactive additives has increased and the exploration for new sources is ongoing. The food processing industry in most countries generates large quantities of byproducts every year, which are frequently abandoned as wastes. However, many of these byproducts are dietary, functional, and potentially novel sources of nutrition. Of the many materials obtained, dietary fibers are particularly promising ingredients that has attracted considerable interest over the past few decades. The reason for this is their significant availability in most food byproducts, low costs, and positive effects for the prevention and treatment of a diverse range of diseases [1]. The fast growing food industry will likely generate an ever-growing amount of byproducts in future including bran, husk, peel, pomace, and other products that are rich in dietary fibers [2]. Therefore, finding optimal use of dietary fibers becomes increasingly imperative.

Ongoing scientific debates exist over the definition of dietary fibers. Currently, with growing understanding about the structure and composition of dietary fibers, this structure has been described as a series of polysaccharides with a degree of polymerization of three or more that are not digested or absorbed by the small intestine. Consequently, dietary fibers were previously regarded as a nonnutritive substance [3]. However, advancements in nutrition and medical science have revealed a promising potential of dietary fibers to reduce the risk of both common and chronic diseases. Due to the important role that dietary fibers play in maintaining human health, these are now recognized as the seventh largest nutrient group in the human body, after proteins, fats, carbohydrates, vitamins, minerals, and water.

Dietary fibers can be classified based on their solubility in water as soluble dietary fibers (SDF) and insoluble dietary fibers (IDF) [4-6]. IDF mainly consist of hemicellulose, cellulose, and lignin and cannot be degraded by enzymes in the human body or dissolved in water (neither warm nor hot). SDF include pectin, oligosaccharides, guar, and gums, most of which are dietary and healthy additives [7]. Currently, dietary fibers are widely added to a broader range of foods, including noodles, bread, milk, beverages, wine, and cookies [8]. These products have been generally acceptable among consumers and are thus profitable for food manufacturers. According 
to published data, more than $50 \%$ of functional foods in supermarkets are fiber-fortified foods and this proportion is increasing [9].

The aim of this review is to summarize recent findings about the biological activity of dietary fibers in the human body, while simultaneously investigating its application in flour products. Substantial studies focused on the effects of various dietary fibers on flour products; however, few comprehensive reviews exist to date. Considering the important role that flour products play in the human diet, the influence of dietary fibers on bread and Chinese noodles has been described in detail and relevant mechanisms have been investigated. Additionally, with the ever-increasing types of fiber-fortified products, we carefully discussed problems that may limit the popularity of some of these and provide potential strategies to improve the acceptance of fiber-rich flour products.

\section{Nutritional Properties of Dietary Fibers}

Since the emergence of the hypothesis of the health function of dietary fibers, many comprehensive studies have been performed combining in vitro, animal, and human experiments. A growing number of reports have reported that dietary fibers can counter the effects of several chronic diseases, thus promoting human health.

2.1. Reducing Glycemic Response. In 1985, Harold et al. [10] first reported that dietary fibers have a hypoglycemic effect, and, since then, additional studies to this regard have been published [11, 12]. For example, the content of available carbohydrate in soybean-fortified flour products was lower than the respective level in normal flour products, suggesting that diabetics could consider dietary fibers as safe sugar substitutes and consequently increase their intake. Comparing the glycemic index (GI) of fiber-fortified foods and normal foods, fiber-fortified foods exhibited lower GI and dietary fibers were reported to present the major functional composition for these are undigested and can thus help lower blood sugar levels [13]. Furthermore, the inhibitory effect that dietary fibers exert on the absorption rate of digestible carbohydrates limits the postprandial blood glucose response, thus reducing plasma glucose levels. Hence, problems related to diabetes can be reduced due to the lowered insulin demand.

2.2. Induction of Microorganisms. Dietary fibers can be used as a fermentation substrate by several species of intestinal bacteria, helping to reduce the $\mathrm{pH}$ value in the gut, restraining the growth of saprophytic bacteria, reducing the accumulation of gut endotoxins, and inhibiting the generation of carcinogens [14]. Generally, dietary fibers promote a suitable microenvironment and create ideal conditions for intestinal flora.

2.3. Antioxidant Effect. Numerous health benefits have been considered to be partly attributed to the antioxidant capacity of phenolic compounds [15]. As a major food source, cereal grains contain abundant phenolic antioxidants, especially phenolic acids. Ferulic acid is one such special phenolic acid, which is the most abundant type of phenolic acid in cereal grains and can be found in cell wall components. Therefore, as the major constituents of plant cell walls, dietary fibers are regarded as an abundant source of phenolic acids. Furthermore, ferulic acid, sinapic acid, and several phenolic acid dehydrodimers were detected in dietary fiber fractions from a wide variety of cereal grains [16]. Due to the existence of phenolic antioxidants, positive correlations have been reported between dietary fibers and a radical scavenging activity [17]. Furthermore, dietary fibers are able to chelate iron and, in the absence of transition metal ions, hydrogen peroxide becomes fairly stable. Nandi and Ghosh [18] compared the antioxidant properties of dietary fibers extracted from defatted sesame husks, rice bran, and flaxseeds and found that these products exhibited different degrees of antioxidant capacity.

2.4. Weight Loss. Excessive caloric intake in the diet led to the currently observed obesity epidemic. Along with the high press, irregular lifestyle, and insufficient exercise of modern society, this tendency is widespread. Observational studies consistently demonstrate that the habitual increased intake of fiber-rich foods is associated with lower body weight [19]. According to a study, dietary fibers may increase fecal moisture and reduce its $\mathrm{pH}$, which may benefit weight management by increasing volume and water content of feces, thus promoting fecal excretion and increasing defecation frequency [20]. Numerous studies found that dietary fibers can increase satiety and decrease appetite, hence indirectly reducing energy intake. Overall, the overwhelming majority of studies reported a positive correlation between fiber-rich food intake and weight loss [21,22].

2.5. Regulating Blood Lipids. As reviewed in several studies, dietary fibers can reduce the risk of atherosclerosis, coronary heart disease, and hypertension [23]. This has been speculated to be related to mesh adsorption [24, 25]. More specifically, highly viscous dietary fibers have high resilience and strength, and, in the presence of water, reticulation will be formed and absorb certain substances [26]. Since the 1960s, this theory has been tested and several organic compounds such as cholesterol have been proposed to be absorbed by dietary fibers and subsequently eliminated from the body as feces.

\section{Supplementation of Foods with Dietary Fibers}

3.1. Effect of DF Enrichment on the Quality of Bread. Bread has a long history in the West and is currently the most common and popular principal food. Thus, the application of dietary fibers to bread has been studied. A wide spectrum of dietary fibers has been evaluated in order to discover a more suitable additive to improve both bread baking quality and nutritional properties. Pea and broad bean pod fibers were studied to understand their effect on dough and resulting bread at different supplementation [27]. The overall results 
show that bread made with pea pod (PP) fibers and broad bean pod (BBP) fibers showed lower water retention capacity, which led to a slight increase in hardness. As for bread quality, increased addition of PP and BBP fibers darkened the bread and caused a large number of nonuniform large gas cells, which resulted in damage to the crumb structure. It was assumed that both fibers from PP and BBP have two opposite effects on bread at an addition level of $1 \mathrm{~g} / 100 \mathrm{~g}$. Overall, these materials are not ideal fiber enhancers. Other fibers were not so readily acceptable in bread such as hazelnut testa fibers [28]. Different qualities of hazelnut testae were added to wheat flour to increase the content of dietary fibers and investigate the effect on baking properties. Sensory descriptive analysis showed that many indexes were not as ideal as those of the control bread: darker color and lower loaf volume reduced overall acceptability. Detrimental effects of hazelnut testa fibers on bread properties were excessive and other fiber resources should be investigated. One study reported that the addition of flaxseed hulls (30\% of dietary fibers), particularly in higher doses, could increase crumb hardness and depress loaf volume. However, nearly all indices were satisfied with addition of up to $4 \%$ flaxseed hull: the colors of both crumb and crust were slightly darker, the aroma and taste remained almost unchanged, and the texture was mildly influenced [29]. Furthermore, adding fenugreek fibers into the bread increased water absorbance and dough strength during farinograph mixing [30]. It was interesting to find that the moisture mobility of fenugreek fiber substituted bread was completely different from the control; thus fenugreek could help maintain bread quality during storage due to the increased water-holding capacity and the ability to prevent starch retrogradation of fenugreek fibers. Despite that, the incorporation of fenugreek fibers was reported to dilute both the gluten protein and wheat starch in flour compared to the control, which may be detrimental to bread texture. Wheat flour was planned to be completely replaced with several types of fibers-rich plant powders such as whole Amaranthus cruentus flour [31]. However, the color was significantly altered and the texture was barely satisfactory, suggesting that dietary fibers should only be used as a partial substitute for wheat flour due to its lack of gluten. Staling is detrimental to bread quality but occurs frequently in the food industry. Wheat flour with high water content was used to retard the staling of starch, and this study suggested fibers with high water-holding capacity such as potato peel to be an ideal additive to solve this particular problem [32]. The water activity of the crust increased during storage due to the migration of water from the crumb to the crust and, thus, the crust moisture content was significantly higher in potato fiber formula breads. In general, potato peel may produce a softer breadcrumb, even if supplied at low levels ( $0.4 \mathrm{~g}$ fibers $/ 100 \mathrm{~g}$ flour). Similar results were reported in other papers: bread prepared by replacing $5 \%$ and $10 \%$ of the flour with banana peel fibers resulted in a better water-holding ability and oilholding ability, thus promoting the production of high quality bread with a relatively long shelf life [33].

As for gluten-free (GF) produce, adding dietary fibers seems to result in improved quality. GF breads are often characterized by low nutritional quality as they merely contain vitamins, minerals, and, in particular, dietary fibers; therefore, an enrichment of GF baked products with dietary fibers seems to be necessary. Sabanis et al. [34] compared selected properties of GF bread formulation with the addition of different cereal fibers (wheat, maize, oat, and barley) and it became clear that all the dietary fibers at $3 \mathrm{~g} / 100 \mathrm{~g}$ and $6 \mathrm{~g} / 100 \mathrm{~g}$ improve all sensory properties of bread and adding $3 \mathrm{~g} / 100 \mathrm{~g}$ maize fibers led to the highest score for overall acceptability. Similar results were also reported in other paper. It was reported that supplementing GF bread with rice bran helps to greatly improve the final bread quality, with fine taste, uniform crumb texture, brown color, and fresh appearance [35]. Hence, developing fiber-rich GF breads to increase acceptability and dietary fiber intake is a meaningful approach.

Tests with fiber resources resulted in different effects on the bread-making process. To summarize, diverse dietary fibers impact bread to varying degrees, and, possibly, dietary fibers with relatively high moisture content may produce improved quality. Apart from these beneficial effects, addition of fibers also exerted negative impacts that dramatically hampered the popularity of high-fiber breads. Therefore, the identification of the ideal dietary fiber resources and their correct dosages remains a necessary requirement.

3.2. Effect of DF Enrichment on the Quality of Chinese Noodles. Noodles are a popular traditional Chinese food and constitute the main part of the Chinese diet [36]. However, the nutritional value of noodles decreased due to increasingly sophisticated processing techniques. To improve the nutritional properties of noodles, it is feasible to add some nutrients, such as dietary fibers. In fiber-fortified noodles, many indexes such as hardness, adhesiveness, cohesiveness, chewiness, and resilience are likely to be significantly changed due to the functional characteristics of dietary fibers. To obtain an ideal formula, the amount of soluble fibers, dough mixing time, and different water levels were investigated, and the results showed that optimized values for soluble fiber level, water level, and mixing time were $3.4 \mathrm{~g} / 100 \mathrm{~g}$ of flour, $36.0 \mathrm{~mL} / 100 \mathrm{~g}$ of flour, and $5 \mathrm{~min}$, respectively. Under these conditions, a softer texture, maximum cohesiveness, chewiness, resilience, and minimum adhesiveness of noodles were obtained, suggesting that the successful utilization of dietary fibers in noodles is possible [37]. Additionally, the effects of particle size and the amount of wheat bran on the quality of dry white Chinese noodles were studied and apparent trends were observed, suggesting significant correlations of the above two factors with noodle quality [38]. Generally, most of the values showed a decreasing trend with increasing addition and size of wheat bran, especially for high addition levels and for using coarse bran. An apparent decrease in peak viscosity and breakdown may alter the quality parameters of cooked dry white Chinese noodles, such as appearance, stickiness, and smoothness. However, the cooking time exhibited an increasing trend and this differed from another study, which reported a shorter required cooking time due to physical damage of the gluten network [39]. As for quality evaluation, remarkable decreasing trends 
of color, taste, and appearance were caused by more than $5 \%$ addition of wheat bran or coarse bran [40]. Another study confirmed that supplementation with arabinoxylans from wheat bran in wheat flour should be relatively low and the appropriate quantity to be added should range within $0.25-1.0 \%$ to promote both cooking characteristics and texture of cooked noodles [41]. At this level, the cookingloss rate was significantly suppressed and exhibited a distinct decreasing trend due to enhanced water absorbing capacity. As the amount of arabinoxylans increased, especially after $1 \%$ arabinoxylans addition, almost all the indicators declined, indicating that excessive addition of dietary fibers may cause undesirable effects on noodles. From the above studies, it can be deduced that the amount of dietary fibers should be controlled at a relative low level, or other food-qualityimproving agents should be added to maintain noodle quality. Several studies suggested that a fineness degree was required; however, the opposite conclusion found that coarse bran was likely to have stronger water-holding power than fine bran [42]. Referring to Fan et al's work, arabinoxylans with a high molecular weight had a better effect on noodles than low molecular weight arabinoxylans. This is largely due to its remarkable ability to retain water and increase S-S content. Hence, finding the optimal granularity will require further evaluation.

3.3. Impact of DF Enrichment on Dough. Overall, research indicated two main reasons for dietary fibers to work in flour products: the unique physicochemical properties of dietary fibers and the effect on starch and protein in wheat flour. Many studies have been performed to evaluate how dietary fibers affect dough and the interaction among starch, protein, and dietary fibers. Among all the functional properties, hydroscopicity plays a crucial role in affecting dough properties such as hardness, cohesiveness, resilience, cooking characteristics, springiness, and uniformity. The porosity surface of dietary fibers could act as active carbon, which leads to high water absorption, thus increasing cooking characteristics of noodles [12]. There are many nonstarch polysaccharides such as mannan, phenolic groups, xylan, and pectin, whose molecular structures are characterized by a large number of hydroxyl groups that allow better water inhibition [43]. When adding a certain level of dietary fibers, a sticky gel network is formed via noncovalent interaction such as hydrogen bonds among main chains. This matrix can work similarly to a gluten network and expand the volume, thus improving uniformity and springiness, leading to a velvety texture of the resulting bread [44]. Evidence indicated that a high water maintaining ability promotes the maintenance of the gluten network and therefore strengthens the tensile performance of noodles [38-40]. Regarding staling, numerous tests showed that the addition of dietary fibers increased the water content of breadcrumbs and led to reduced deterioration during storage. The interaction of proteins, starches, and dietary fibers in cereal products could affect texture properties, and studies have reported a vulnerable fiber-starch-protein network structure. In the presence of dietary fibers, and particularly when the addition is below a relatively low level, this structure may emerge and thus retain more water and suppress excess expansion and diffusion of starch. However, this matrix may be easily destroyed when the addition exceeds a certain threshold. As a result, the stability of the gluten network may be hindered [41]. Dietary fibers can significantly affect the properties of dough in both positive and negative ways. As the amount, particle size, variety, and solubility vary, the influence of dietary fibers on flour products differs. Studies about the reverse impact of dietary fibers on gluten reported a dilution effect on the gluten network, which could reduce the gasholding capacity and thus limit the expansion of air cells [45]. Other studies reported that the consistency of wheat gluten may be damaged by fibers, adversely affecting the specific volume of the bread [46]. Furthermore, considerable research findings supported by Fourier transform infrared spectroscopy, nuclear magnetic resonance, infrared spectroscopy, and Raman spectrum suggested that dietary fibers can compete with gluten to impede the formation of a gluten network and modify the secondary structure of gluten proteins [47-49]. Dietary fibers are chiefly composed of IDF including cellulose, hemicellulose, and xylogen, supplying more than three-quarters of some natural dietary fibers. As a consequence, the gluten matrix may be subjected to physical damage. Some studies indicated that IDF can break the bubble interface in fermented dough and damage the stability and uniformity of the gluten matrix [50,51]. Based on the above analysis, dough is a complex system, and, given the sophisticated relationship of dietary fibers, starch, and proteins, further study is required to further our understanding of the effects of dietary fibers on dough properties.

\section{Problems and Solutions of Dietary Fibers in Flour Products}

4.1. Dark Color. Many studies reported a darker color of fiber-rich products. It is true that dietary fibers can create a dull color, thus reducing acceptability. Especially for principle foods such as noodles, steamed buns, and breads, the presence of unattractive color potentially limits the public acceptability of these products. Therefore, optimal strategies for decolorization are required. Since pypocholoride could produce residual chlorine and result in a undesired chlorine smell in the modern decoloration industry, hydrogen peroxide is more frequently used. Compared to pypocholoride, hydrogen peroxide is a more secure decolorizer that mainly ionizes hydrogen ions and peroxide ions in water. For example, apple pomace is a byproduct of the beverage industry; however, it is rich in highly active dietary fibers. During the manufacturing process, the integrity of cells may be greatly destroyed and many enzymes such as polyphenol oxidases may be released, leading to brown coloring and limiting its incorporation in food. An experiment was conducted to investigate the bleaching of apple pomace by hydrogen peroxide, showing that alkaline peroxide treatment allowed a more even and better bleaching effect compared to sodium chlorite [52]. The conditions of bleaching were also studied 
and it was revealed that high $\mathrm{pH}$ and high concentrations of hydrogen peroxide affect bleaching, yields, and the swelling capacity. However, low yields were observed, suggesting alternative methods are required to improve the bleaching procedure without decreasing yields and sacrificing quality. A key reason for excessive addition of peroxide is that it is a labile compound that is easily affected by transition metals [53]. To solve this problem, experiments have been performed utilizing chitosan, the presence of which may absorb several transition metals such as iron, copper, and manganese and increase deacetylation [54]. These properties inhibit the degradation of peroxide and consequently accelerate the bleaching process. Further studies will be required to determine the ideal conditions to reduce the required amount of hydrogen peroxide and decrease bleaching time.

4.2. Rough Texture. As was mentioned above, dietary fibers are an indigestible substance with a hard and coarse texture. When added to food, particularly to flour products, a rough taste can be generated, consequently limiting the acceptance of these products. The reduction of particle size via micron technology could help to promote intestinal health and other functional properties, including water-holding capacity, water retention capacity, oil binding capacity, and swelling capacity. Additionally, with smaller particle sizes, the fiber structure could be broken down, thus exposing an increased surface area for bacterial growth and allowing a remarkable increase of bacterial mass and the amount of fecal output $[55,56]$. Physical, chemical, and biological methods can all be applied to reduce particle size. Commonly used technologies include the superfine grinding technology, as well as enzyme, and fermentation approaches. Of these, various micronization methods have been applied for the processing of functional foods. Several common grinding methods exist: ball milling, jet milling, and high-pressure micronization, all used to reduce the particle sizes of dry material to different micron scales [55]. All treatments could successfully diminish the sizes of the insoluble fiber particles to different microsizes; however, there were significant differences in the required processing time. More specifically, ball milling and jet milling reduced particle sizes to $90.6 \%$ and $78.6 \%$, respectively; however, jet milling took only a few seconds compared to ten hours of ball milling. Hence, jet milling seems a more efficient approach. High-pressure micronization treatment can pulverize a fine powder to $7.23 \mu \mathrm{m}$, but there are only few studies that utilize this technology [57]. Thus, further studies using this method are required. A further way to produce a smooth texture is the microfluidization treatment. This approach has been proven beneficial for the dispersion stability of wheat bran in water. With smaller particle size, better dispersion occurred due to the restrained formation of dense structures, which could help to produce uniform and stable dispersion in food [58]. Combined with the satisfying dispersion stability, an apparent decreasing trend of corn bran particle size was also observed; however, the degree of dissociation after microfluidization was lower than that after ball milling and jet milling. This suggests that microfluidization is not as good as both milling treatments to produce a finely ground bran [59]. The rough texture of fiberenriched foods may be caused by many factors. In addition to fineness, dispersion and uniformity should also be considered, and combining methods may help to improve milling efficiency. As reported, several notable side effects such as improved water-holding capacity, swelling capacity, and oilholding capacity were also observed, due to the substantially increased specific surface area and porosity caused by highpressure microfluidization or other micronization methods. These results suggest ultrafine grinding to be an advantageous method to both produce smaller fragments and enhance other functional properties [60,61].

4.3. Poor Solubility. The optimal mass ratio of SDF and IDF was reported to be 1:3 and real ratios in food can even reach $1: 9$, which severely affects its digestion and absorption in the human body as well as its physicochemical properties in cereal products [62]. To some extent, a high SDF content may be more efficient and acceptable due to it being more inclined to form gels and being readily incorporated into foods [6367]. In contrast, IDF promotes gastrointestinal motility and fecal output; however, it also exerts adverse effects on foods [68]. Extrusion is a thermal processing method that involves the application of high heat, high pressure, and shear forces and can be used to treat uncooked masses such as cereal foods [69]. Compared to other treatments, it yields more SDF at a shorter processing time, low energy, and low cost [70]. Zhang et al. [71] optimized the extrusion conditions for yields of oat bran SDF and obtained $14.2 \mathrm{~g} / 100 \mathrm{~g}$ at $140^{\circ} \mathrm{C}$ incubation temperature and $10 \%$ feed moisture. In addition to the frequently used extrusion processing, a modified technology named blasting processing has been introduced, which has shown great potential in extracting SDF from wheat bran and soybean residue $[72,73]$. In Chen et al's work, using this technology produced almost 10-fold increased SDF values, which supplied a satisfactory result. The amount of soybean residue SDF was considerably enhanced from $2.6 \pm 0.3 \%$ to $30.1 \pm 0.6 \%$ with treatment at $170^{\circ} \mathrm{C}$ at $150 \mathrm{r} / \mathrm{min}$ extrusion screw speed, suggesting excellent efficacy of blasting processing. However, a relatively small change from $9.82 \pm 0.16 \%(\mathrm{w} / \mathrm{w}, \%)$ to $16.7 \pm 0.28 \%(\mathrm{w} / \mathrm{w}, \%)$ was reported for wheat bran [73] and the increment seemed not severe in contrast to Chen et al's work. This might be attributed to differences in raw materials. Accordingly, using blasting extrusion processing to produce SDF shows great potential [69]. Several IDF dissolved in water after ultrafine grinding treatment, suggesting that this technology could be used to simultaneously produce two types of effects: decreasing IDF particle sizes and improving solubilization. In previous studies, almost all micron technologies promoted solubility to varying degrees by increasing the surface area exposure and significantly damaging fiber structures [56]. Similarly, microfluidization may create a puffed morphology and a loose microstructure, thus enhancing the solubility of IDF. In addition to the above physical methods, some enzymes such as cellulose and hemicellulose can promote solubilization via collapsing the hard cell wall and lowering 
molecular weight. Due to more sophisticated procedures of enzymatic process, physical means are more frequently used.

\section{Conclusions}

This paper summarizes the nutritive properties and applications of dietary fibers. Dietary fibers receive increasing interest due to their great potential for treating several diseases and, consequently, substantial studies have been performed to develop fiber-rich products. However, several problems such as dark color and rough texture have been severely limiting the popularity of fiber-fortified products; therefore, relevant strategies have also been discussed to address these problems. Generally, further studies should be conducted to effectively solve these problems and to better use dietary fibers in grain products.

\section{Conflicts of Interest}

The authors declare that there are no conflicts of interest regarding the publication of this paper.

\section{Acknowledgments}

The present research was financially supported by Henan Province Colleges and Universities Young Backbone Teacher Plan (2016GGJS-070), Key Scientific and Technological Project of Henan Province (172102110008), and Opening Foundation of Province Key Laboratory of Transformation and Utilization of Cereal Resource in Henan University of Technology (24400036 and 24400031).

\section{References}

[1] E. Betoret, N. Betoret, D. Vidal, and P. Fito, "Functional foods development: trends and technologies," Trends in Food Science and Technology, vol. 22, no. 9, pp. 498-508, 2011.

[2] L. H. McKee and T. A. Latner, "Underutilized sources of dietary fiber: a review," Plant Foods for Human Nutrition, vol. 55, no. 4, pp. 285-304, 2000.

[3] S. K. Sharma, S. Bansal, M. Mangal, A. K. Dixit, R. K. Gupta, and A. Mangal, "Utilization of food processing by-products as dietary, functional, and novel fiber: a review," Critical Reviews in Food Science and Nutrition, vol. 56, no. 10, pp. 1647-1661, 2015.

[4] W. Grajek, A. Olejnik, and A. Sip, "Probiotics, prebiotics and antioxidants as functional foods," Acta Biochimica Polonica, vol. 52, no. 3, pp. 665-671, 2005.

[5] R. Rodríguez, A. Jiménez, J. Fernández-Bolaños, R. Guillén, and A. Heredia, "Dietary fibre from vegetable products as source of functional ingredients," Trends in Food Science and Technology, vol. 17, no. 1, pp. 3-15, 2006.

[6] M. Kale, D. Pai, B. Hamaker, and O. Campanella, "Incorporation of fibers in foods: a food engineering challenge," in Food Engineering Interfaces, Food Engineering Series, pp. 69-98, Springer, New York, NY, USA, 2011.

[7] D. Dhingra, M. Michael, H. Rajput, and R. T. Patil, "Dietary fibre in foods: a review," Journal of Food Science and Technology, vol. 49, no. 3, pp. 255-266, 2012.

[8] M. Reicks, S. Jonnalagadda, A. M. Albertson, and N. Joshi, "Total dietary fiber intakes in the US population are related to whole grain consumption: results from the National Health and Nutrition Examination Survey 2009 to 2010," Nutrition Research, vol. 34, no. 3, pp. 226-234, 2014.

[9] E. B. Giuntini and E. W. Menezes, Funções Plenamente Reconhecidas de Nutrientes: Fibra Alimentar, Série de Publicações International Life Sciences Institute do Brasil, International Life Sciences Institute do Brasil, 2011.

[10] M. R. Harold, R. D. Reeves, M. S. Bolze, R. A. Guthrie, and D. W. Guthrie, "Effect of dietary fiber in insulin-dependent diabetics: insulin requirements and serum lipids," Journal of the American Dietetic Association, vol. 85, no. 11, pp. 1455-1460, 1985.

[11] F. Saura-Calixto, A. Garcia-Alonso, I. Goni, and L. Bravo, "In vitro determination of the indigestible fraction in foods: an alternative to dietary fiber analysis," Journal of Agricultural and Food Chemistry, vol. 48, no. 8, pp. 3342-3347, 2000.

[12] F. Guillon and M. Champ, "Structural and physical properties of dietary fibres, and consequences of processing on human physiology," Food Research International, vol. 33, no. 3-4, pp. 233-245, 2000.

[13] F. Lu, Y. Liu, and B. Li, "Okara dietary fiber and hypoglycemic effect of okara foods," Bioactive Carbohydrates and Dietary Fibre, vol. 2, no. 2, pp. 126-132, 2013.

[14] J. Y. Thebaudin, A. C. Lefebvre, M. Harrington, and C. M. Bourgeois, "Dietary fibres: nutritional and technological interest," Trends in Food Science and Technology, vol. 8, no. 2, pp. 41-48, 1997.

[15] R. H. Liu, "Whole grain phytochemicals and health," Journal of Cereal Science, vol. 46, no. 3, pp. 207-219, 2007.

[16] D. Dobberstein and M. Bunzel, "Separation and detection of cell wall-bound ferulic acid dehydrodimers and dehydrotrimers in cereals and other plant materials by reversed phase highperformance liquid chromatography with ultraviolet detection," Journal of Agricultural and Food Chemistry, vol. 58, no. 16, pp. 8927-8935, 2010.

[17] J. Pérez-Jiménez, J. Serrano, M. Tabernero et al., "Bioavailability of phenolic antioxidants associated with dietary fiber: plasma antioxidant capacity after acute and long-term intake in humans," Plant Foods for Human Nutrition, vol. 64, no. 2, pp. 102-107, 2009.

[18] I. Nandi and M. Ghosh, "Studies on functional and antioxidant property of dietary fibre extracted from defatted sesame husk, rice bran and flaxseed," Bioactive Carbohydrates and Dietary Fibre, vol. 5, no. 2, pp. 129-136, 2015.

[19] D. Mudgil and S. Barak, "Composition, properties and health benefits of indigestible carbohydrate polymers as dietary fiber: a review," International Journal of Biological Macromolecules, vol. 61, pp. 1-6, 2013.

[20] F. T. Macagnan, L. R. D. Santos, B. S. Roberto, F. A. De Moura, M. Bizzani, and L. P. Da Silva, "Biological properties of apple pomace, orange bagasse and passion fruit peel as alternative sources of dietary fibre," Bioactive Carbohydrates and Dietary Fibre, vol. 6, no. 1, pp. 1-6, 2015.

[21] M. O. Weickert and A. F. H. Pfeiffer, "Metabolic effects of dietary fiber consumption and prevention of diabetes," Journal of Nutrition, vol. 138, no. 3, pp. 439-442, 2008.

[22] H. Tadesse and R. Luque, "Advances on biomass pretreatment using ionic liquids: an overview," Energy and Environmental Science, vol. 4, no. 10, pp. 3913-3929, 2011.

[23] M. N. Ballesteros, R. M. Cabrera, M. S. Saucedo, G. M. YepizPlascencia, M. I. Ortega, and M. E. Valencia, "Dietary fiber and lifestyle influence serum lipids in free living adult men," Journal 
of the American College of Nutrition, vol. 20, no. 6, pp. 649-655, 2001.

[24] S. Ruottinen, H. K. Lagström, H. Niinikoski et al., "Dietary fiber does not displace energy but is associated with decreased serum cholesterol concentrations in healthy children," American Journal of Clinical Nutrition, vol. 91, no. 3, pp. 651-661, 2010.

[25] Y. Hong, W. Zi-jun, X. Jian, D. Ying-Jie, and M. Fang, "Development of the dietary fiber functional food and studies on its toxicological and physiologic properties," Food and Chemical Toxicology, vol. 50, no. 9, pp. 3367-3374, 2012.

[26] E. Theuwissen and R. P. Mensink, "Water-soluble dietary fibers and cardiovascular disease," Physiology and Behavior, vol. 94, no. 2, pp. 285-292, 2008.

[27] L. Belghith Fendri, F. Chaari, M. Maaloul et al., "Wheat bread enrichment by pea and broad bean pods fibers: effect on dough rheology and bread quality," LWT-Food Science and Technology, vol. 73, pp. 584-591, 2016.

[28] M. Anil, "Using of hazelnut testa as a source of dietary fiber in breadmaking," Journal of Food Engineering, vol. 80, no. 1, pp. 6167, 2007.

[29] Ł. Sęczyk, M. Świeca, D. Dziki, A. Anders, and U. GawlikDziki, "Antioxidant, nutritional and functional characteristics of wheat bread enriched with ground flaxseed hulls," Food Chemistry, vol. 214, pp. 32-38, 2017.

[30] G. Huang, Q. Guo, C. Wang, H. H. Ding, and S. W. Cui, "Fenugreek fibre in bread: effects on dough development and bread quality," LWT-Food Science and Technology, vol. 71, pp. 274-280, 2016.

[31] J. M. Sanz-Penella, M. Wronkowska, M. Soral-Smietana, and M. Haros, "Effect of whole amaranth flour on bread properties and nutritive value," LWT_Food Science and Technology, vol. 50, no. 2, pp. 679-685, 2013.

[32] E. Curti, E. Carini, A. Diantom, and E. Vittadini, “The use of potato fibre to improve bread physico-chemical properties during storage," Food Chemistry, vol. 195, pp. 64-70, 2016.

[33] N. S. Eshak, "Sensory evaluation and nutritional value of balady flat bread supplemented with banana peels as a natural source of dietary fiber," Annals of Agricultural Sciences, vol. 61, no. 2, pp. 229-235, 2016.

[34] D. Sabanis, D. Lebesi, and C. Tzia, "Effect of dietary fibre enrichment on selected properties of gluten-free bread," LWT-Food Science and Technology, vol. 42, no. 8, pp. 1380-1389, 2009.

[35] Y. Phimolsiripol, A. Mukprasirt, and R. Schoenlechner, "Quality improvement of rice-based gluten-free bread using different dietary fibre fractions of rice bran," Journal of Cereal Science, vol. 56, no. 2, pp. 389-395, 2012.

[36] N. Zhang and G. Ma, "Noodles, traditionally and today," Journal of Ethnic Foods, vol. 3, no. 3, pp. 209-212, 2016.

[37] D. Mudgil, S. Barak, and B. S. Khatkar, "Optimization of textural properties of noodles with soluble fiber, dough mixing time and different water levels," Journal of Cereal Science, vol. 69, pp. 104110, 2016.

[38] J. J. Liu, Z. H. He, Z. D. Zhao, R. J. Peña, and S. Rajaram, "Wheat quality traits and quality parameters of cooked dry white Chinese noodles," Euphytica, vol. 131, no. 2, pp. 147-154, 2003.

[39] F. A. Manthey, S. R. Yalla, T. J. Dick, and M. Badaruddin, "Extrusion properties and cooking quality of spaghetti containing buckwheat bran flour," Cereal Chemistry, vol. 81, no. 2, pp. 232236, 2004.
[40] J. S. Chen, M. J. Fei, C. L. Shi et al., "Effect of particle size and addition level of wheat bran on quality of dry white Chinese noodles," Journal of Cereal Science, vol. 53, no. 2, pp. 217-224, 2011.

[41] L. Fan, S. Ma, X. Wang, and X. Zheng, "Improvement of Chinese noodle quality by supplementation with arabinoxylans from wheat bran," International Journal of Food Science and Technology, vol. 51, no. 3, pp. 602-608, 2016.

[42] D. Zhang and W. R. Moore, "Effect of wheat bran particle size on dough rheological properties," Journal of the Science of Food and Agriculture, vol. 74, no. 4, pp. 490-496, 1997.

[43] C. M. Rosell, J. A. Rojas, and C. Benedito de Barber, "Influence of hydrocolloids on dough rheology and bread quality," Food Hydrocolloids, vol. 15, no. 1, pp. 75-81, 2001.

[44] D. N. Abang Zaidel, N. L. Chin, R. Abdul Rahman, and R. Karim, "Rheological characterisation of gluten from extensibility measurement," Journal of Food Engineering, vol. 86, no. 4, pp. 549-556, 2008.

[45] V. Stojceska, Flour and Breads and Their Fortification in Health and Disease Prevention, American Association of Cereal Chemists, Eagan, Minn, USA, 2011.

[46] M. Salmenkallio-Marttila, K. Katina, and K. Autio, "Effects of bran fermentation on quality and microstructure of high-fiber wheat bread," Cereal Chemistry, vol. 78, no. 4, pp. 429-435, 2001.

[47] J. Li, G. G. Hou, Z. Chen, A.-L. Chung, and K. Gehring, "Studying the effects of whole-wheat flour on the rheological properties and the quality attributes of whole-wheat saltine cracker using SRC, alveograph, rheometer, and NMR technique," LWT-Food Science and Technology, vol. 55, no. 1, pp. 43-50, 2014.

[48] J. E. Bock and S. Damodaran, "Bran-induced changes in water structure and gluten conformation in model gluten dough studied by Fourier transform infrared spectroscopy," Food Hydrocolloids, vol. 31, no. 2, pp. 146-155, 2013.

[49] A. S. Sivam, D. Sun-Waterhouse, C. O. Perera, and G. I. N. Waterhouse, "Application of FT-IR and Raman spectroscopy for the study of biopolymers in breads fortified with fibre and polyphenols," Food Research International, vol. 50, no. 2, pp. 574-585, 2013.

[50] K. Poutanen, N. Sozer, and G. Della Valle, "How can technology help to deliver more of grain in cereal foods for a healthy diet?" Journal of Cereal Science, vol. 59, no. 3, pp. 327-336, 2014.

[51] A. Turbin-Orger, E. Boller, L. Chaunier, H. Chiron, G. Della Valle, and A.-L. Réguerre, "Kinetics of bubble growth in wheat flour dough during proofing studied by computed X-ray microtomography," Journal of Cereal Science, vol. 56, no. 3, pp. 676683, 2012.

[52] C. M. G. C. Renard, Y. Rohou, C. Hubert, G. Della Valle, J.-F. Thibault, and J.-P. Savina, "Bleaching of apple pomace by hydrogen peroxide in alkaline conditions: optimisation and characterisation of the products," LWT-Food Science and Technology, vol. 30, no. 4, pp. 398-405, 1997.

[53] A. Wuorimaa, R. Jokela, and R. Aksela, "Recent developments in the stabilization of hydrogen peroxide bleaching of pulps: an overview," Nordic Pulp and Paper Research Journal, vol. 21, no. 4, pp. 435-443, 2006.

[54] Z. Li, H. Dou, Y. Fu, and M. Qin, "Improving the hydrogen peroxide bleaching efficiency of aspen chemithermomechanical pulp by using chitosan," Carbohydrate Polymers, vol. 132, pp. 430-436, 2015.

[55] C.-F. Chau, Y.-T. Wang, and Y.-L. Wen, "Different micronization methods significantly improve the functionality of carrot 
insoluble fibre," Food Chemistry, vol. 100, no. 4, pp. 1402-1408, 2007.

[56] F. Zhu, B. Du, R. Li, and J. Li, "Effect of micronization technology on physicochemical and antioxidant properties of dietary fiber from buckwheat hulls," Biocatalysis and Agricultural Biotechnology, vol. 3, no. 3, pp. 30-34, 2014.

[57] S.-C. Wu, P.-J. Chien, M.-H. Lee, and C.-F. Chau, "Particle size reduction effectively enhances the intestinal health-promotion ability of an orange insoluble fiber in hamsters," Journal of Food Science, vol. 72, no. 8, pp. S618-S621, 2007.

[58] N. Rosa-Sibakov, J. Sibakov, P. Lahtinen, and K. Poutanen, "Wet grinding and microfluidization of wheat bran preparations: improvement of dispersion stability by structural disintegration," Journal of Cereal Science, vol. 64, pp. 1-10, 2015.

[59] T. Wang, X. Sun, Z. Zhou, and G. Chen, "Effects of microfluidization process on physicochemical properties of wheat bran," Food Research International, vol. 48, no. 2, pp. 742-747, 2012.

[60] B. Du, F. Zhu, and B. Xu, "Physicochemical and antioxidant properties of dietary fibers from Qingke (hull-less barley) flour as affected by ultrafine grinding," Bioactive Carbohydrates and Dietary Fibre, vol. 4, no. 2, pp. 170-175, 2014.

[61] J. Chen, D. Gao, L. Yang, and Y. Gao, "Effect of microfluidization process on the functional properties of insoluble dietary fiber," Food Research International, vol. 54, no. 2, pp. 1821-1827, 2013.

[62] D. Z. Bliss, "Dietary fiber in conservative management of chronic renal failure," Pediatric Nephrology, vol. 19, no. 10, pp. 1069-1070, 2004.

[63] M. Galisteo, J. Duarte, and A. Zarzuelo, "Effects of dietary fibers on disturbances clustered in the metabolic syndrome," Journal of Nutritional Biochemistry, vol. 19, no. 2, pp. 71-84, 2008.

[64] P. Kethireddipalli, Y.-C. Hung, R. D. Phillips, and K. H. McWatters, "Evaluating the role of cell wall material and soluble protein in the functionality of cowpea (Vigna unguiculata) pastes," Journal of Food Science, vol. 67, no. 1, pp. 53-59, 2002.

[65] T. Feng, Q. Su, H. Zhuang, R. Ye, Z. Gu, and Z. Jin, "Ghost structures, pasting, rheological and textural properties between mesona blumes gum and various starches," Journal of Food Quality, vol. 37, no. 2, pp. 73-82, 2014.

[66] T. Feng, R. Ye, H. Zhuang et al., "Physicochemical properties and sensory evaluation of Mesona Blumes gum/rice starch mixed gels as fat-substitutes in Chinese Cantonese-style sausage," Food Research International, vol. 50, no. 1, pp. 85-93, 2013.

[67] D. J. A. Jenkins, C. W. C. Kendall, D. A. Faulkner et al., "Assessment of the longer-term effects of a dietary portfolio of cholesterol-lowering foods in hypercholesterolemia," American Journal of Clinical Nutrition, vol. 83, no. 3, pp. 582-591, 2006.

[68] F. Robin, H. P. Schuchmann, and S. Palzer, "Dietary fiber in extruded cereals: limitations and opportunities," Trends in Food Science and Technology, vol. 28, no. 1, pp. 23-32, 2012.

[69] J. H. Kim, E. J. Tanhehco, and P. K. W. Ng, "Effect of extrusion conditions on resistant starch formation from pastry wheat flour," Food Chemistry, vol. 99, no. 4, pp. 718-723, 2006.

[70] A. Faraj, T. Vasanthan, and R. Hoover, "The effect of extrusion cooking on resistant starch formation in waxy and regular barley flours," Food Research International, vol. 37, no. 5, pp. 517525, 2004.

[71] M. Zhang, X. Bai, and Z. Zhang, "Extrusion process improves the functionality of soluble dietary fiber in oat bran," Journal of Cereal Science, vol. 54, no. 1, pp. 98-103, 2011.
[72] Y. Chen, R. Ye, L. Yin, and N. Zhang, "Novel blasting extrusion processing improved the physicochemical properties of soluble dietary fiber from soybean residue and in vivo evaluation," Journal of Food Engineering, vol. 120, no. 1, pp. 1-8, 2014.

[73] X. Yan, R. Ye, and Y. Chen, "Blasting extrusion processing: the increase of soluble dietary fiber content and extraction of soluble-fiber polysaccharides from wheat bran," Food Chemistry, vol. 180, pp. 106-115, 2015. 

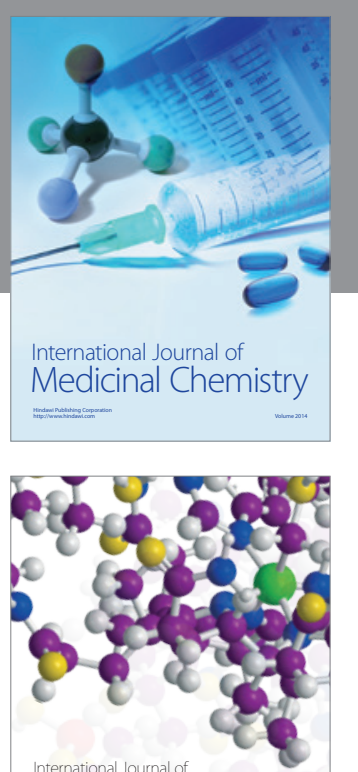

Carbohydrate Chemistry

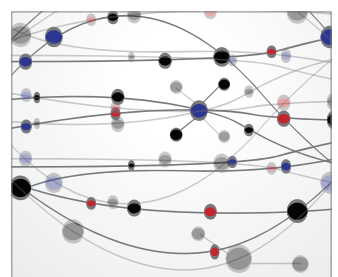

The Scientific World Journal
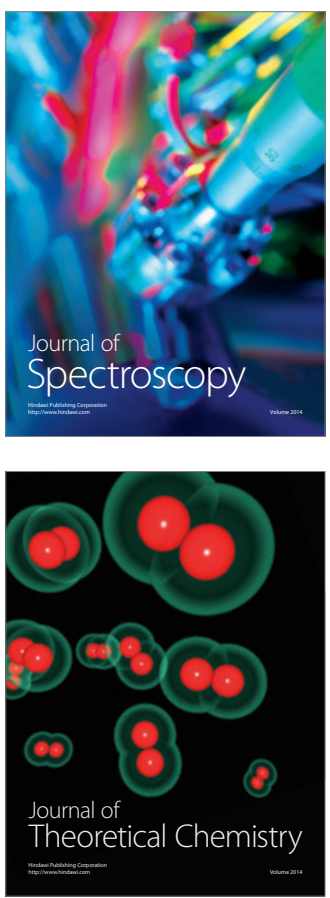
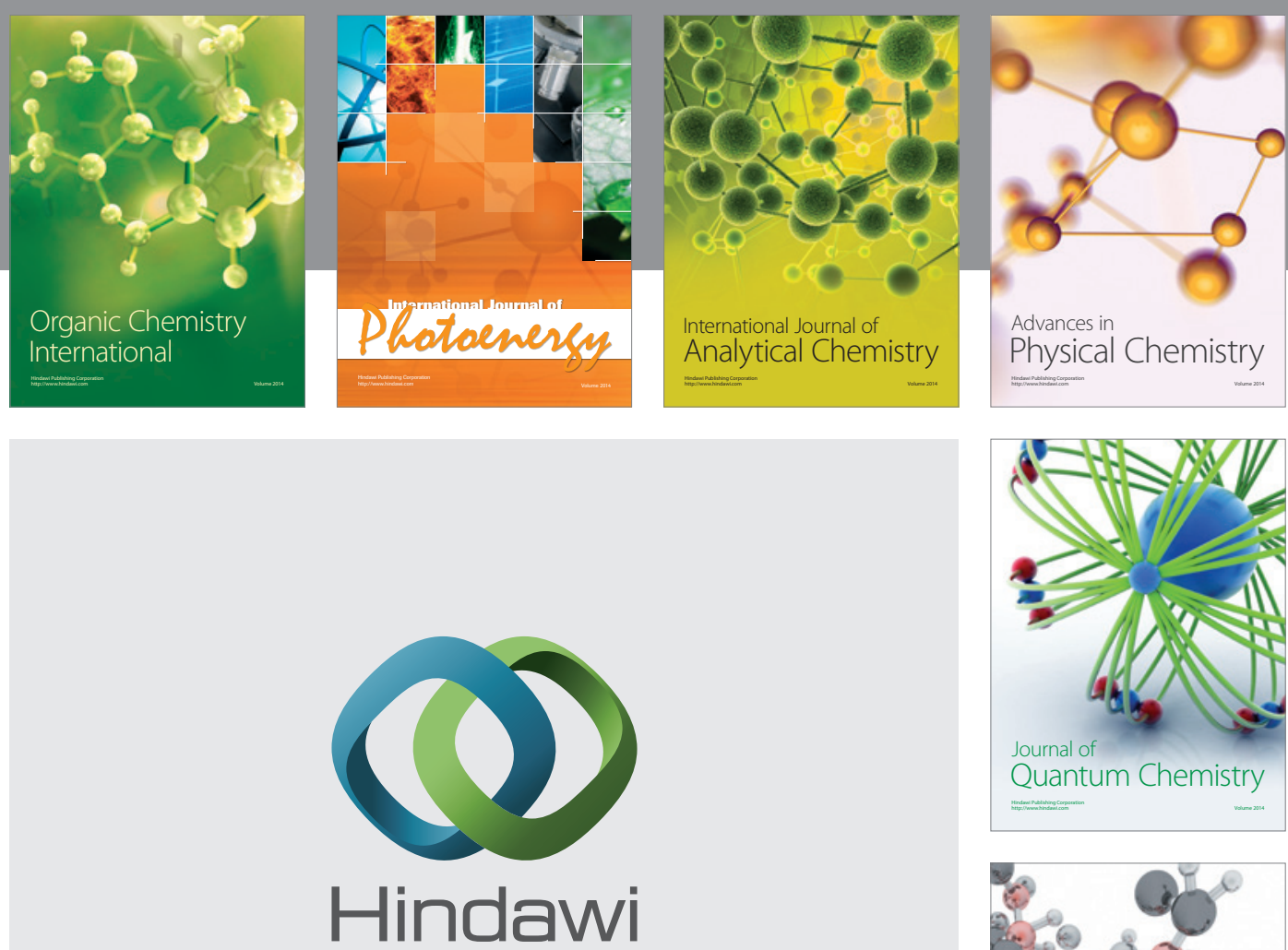

Submit your manuscripts at

https://www.hindawi.com

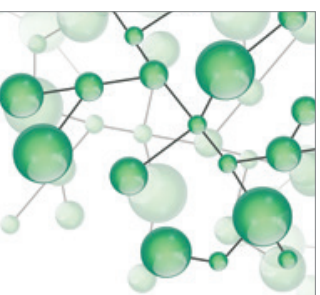

International Journal of

Inorganic Chemistry
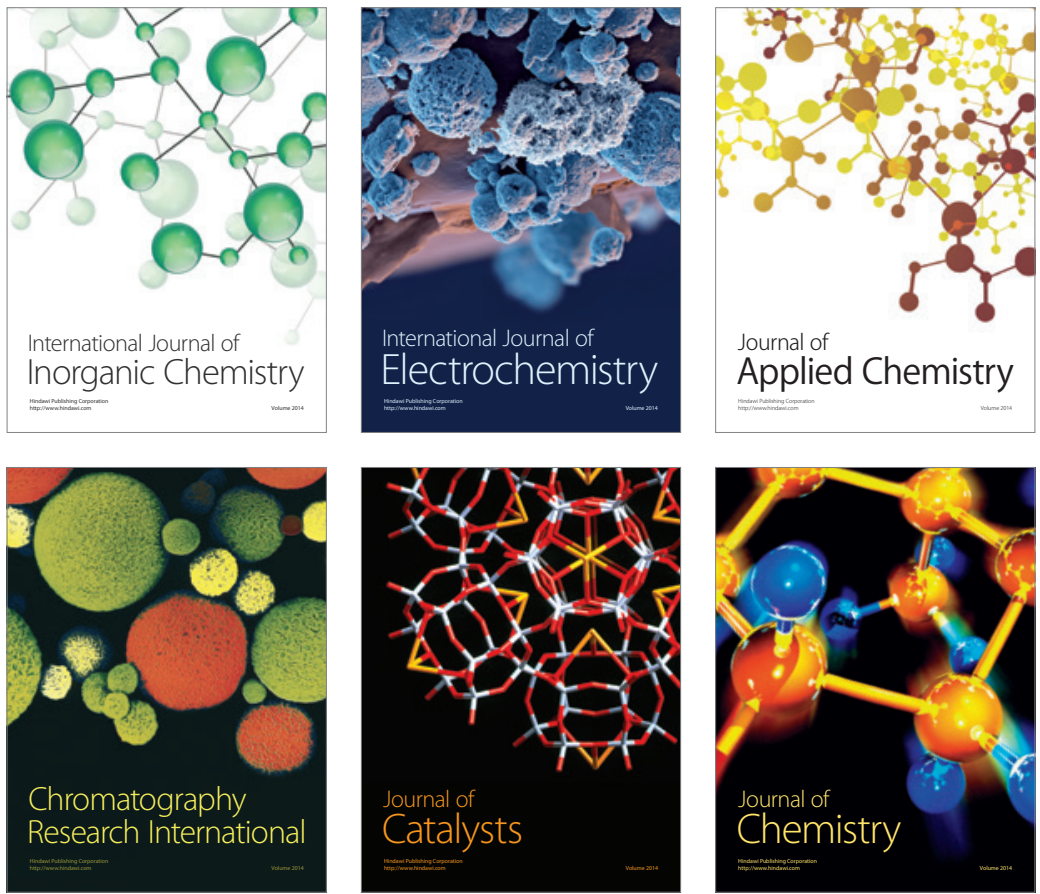

Journal of

Applied Chemistry
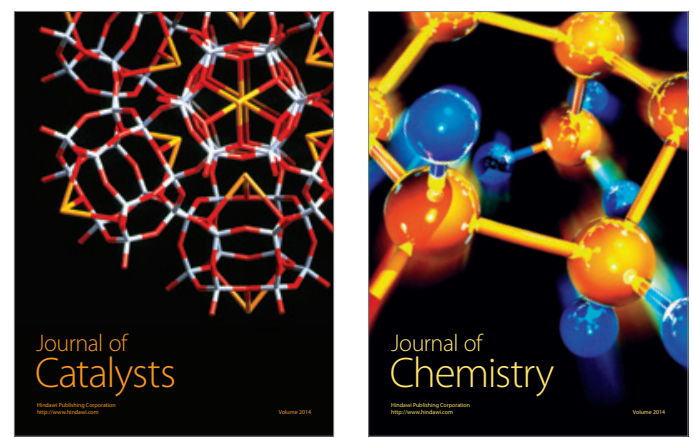
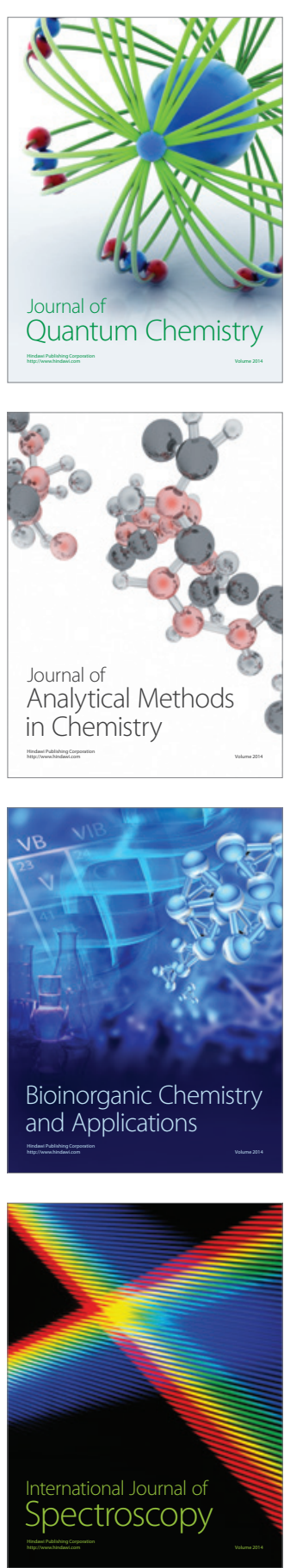